\title{
Spirulina platensis Consumption Prevents Obesity and Improves the Deleterious Effects on Intestinal Reactivity in Rats Fed a Hypercaloric Diet
}

\author{
Anderson Fellyp Avelino Diniz $\left(\mathbb{D},{ }^{1}\right.$ Brena Freire de Oliveira Claudino, ${ }^{2}$ \\ Manoel Vieira Duvirgens, ${ }^{2}$ Petruska Pessoa da Silva Souza, ${ }^{2}$ Paula Benvindo Ferreira, ${ }^{1}$ \\ Francisco Fernandes Lacerda Júnior, ${ }^{1}$ Adriano Francisco Alves, ${ }^{3}$ \\ and Bagnólia Araújo da Silva ${ }^{1,4}$ \\ ${ }^{1}$ Postgraduate Program in Natural and Synthetic Products Bioactive/Health Sciences Center, Federal University of Paraiba, \\ João Pessoa, Paraíba, Brazil \\ ${ }^{2}$ Health Sciences Center, Federal University of Paraiba, João Pessoa, Paraíba, Brazil \\ ${ }^{3}$ General Pathology Laboratory-Health Sciences Center-Department of Physiology and Pathology, Federal University of Paraiba, \\ João Pessoa, Paraíba, Brazil \\ ${ }^{4}$ Pharmaceutical Sciences Department/Health Sciences Center/Federal University of Paraiba, João Pessoa, Paraíba, Brazil
}

Correspondence should be addressed to Anderson Fellyp Avelino Diniz; andersonfellyp@gmail.com

Received 27 April 2021; Revised 9 July 2021; Accepted 15 July 2021; Published 28 July 2021

Academic Editor: Kai Wang

Copyright (C) 2021 Anderson Fellyp Avelino Diniz et al. This is an open access article distributed under the Creative Commons Attribution License, which permits unrestricted use, distribution, and reproduction in any medium, provided the original work is properly cited.

\begin{abstract}
The consumption of hypercaloric diets is related to the development of obesity, favoring the etiology of gastrointestinal disorders. In this context, Spirulina platensis (SP), some blue-green algae with antioxidant action, appears as a potential therapeutic alternative to prevent obesity and associated intestinal disorders. Thus, the present study is aimed at evaluating the deleterious effects of the hypercaloric diet on the contractile and relaxing reactivity of the ileum of rats, as well as the possible preventive mechanisms of dietary supplementation with SP. Wistar rats were divided into three groups: fed a standard diet (SD), a hypercaloric diet (HCD), and/or supplemented with $25 \mathrm{mg} / \mathrm{kg}$ SP (HCD + SP25) for 8 weeks. The hypercaloric diet was effective in promoting obesity in rats, as well as decreasing potency and ileal relaxing and contractile efficacy. In contrast, dietary supplementation with SP was able to prevent some of the parameters of experimental obesity. In addition, SP prevented the reduction of intestinal reactivity, possibly due to a positive modulation of voltage-gated calcium channels $\left(\mathrm{Ca}_{\mathrm{V}}\right)$ and negative regulation of muscarinic receptors (M3). Thus, food supplementation with Spirulina platensis becomes a promising alternative in the prevention of gastrointestinal diseases induced and/or aggravated by obesity.
\end{abstract}

\section{Introduction}

Defined as the abnormal and/or excessive deposition of body fat, which directly interferes with the individual's health, obesity is a chronic noncommunicable disease caused by the energy imbalance between consumption and caloric expenditure, representing an important risk factor for development of cardiovascular diseases, type 2 diabetes mellitus, musculoskeletal disorders, and some types of cancer [1-4].
The causes can be influenced by genetic, hormonal, and environmental factors, especially those related to poor eating habits, determined by the consumption of hypercaloric diets leading to increased rates of obesity and overweight and consequently to the development of various gastrointestinal disorders $[5,6]$.

Thus, with the growing global obesity epidemic, researchers have turned their attention to studies that demonstrate the relationship between obesity and the main 
metabolic and endocrine disorders that affect the gastrointestinal system (gastroesophageal reflux disease, dyspepsia, constipation, bowel syndrome irritable, and diarrhea) that contribute to the existence of similar proinflammatory mechanisms, linking both diseases [7-9]. In addition, preclinical studies report that obesity impairs inhibitory neuromuscular transmission and relaxation of enteric smooth muscle, in addition to changes in intestinal motility [10].

In this context, the marine environment represents a rich therapeutic arsenal composed of several organisms that function as sources of bioactive metabolites, with great potential for the discovery of new drugs [11]. Among these organisms, in recent years as previous marine algae gaining prominence, being increasingly inserted in human food, demonstrating antiobesity effects, mainly to its nutritional composition of bioactive compounds, photosynthetic pigments, sterols, polyunsaturated fatty acids, vitamins, minerals, fiber, and proteins, used as nutraceuticals and/or food supplements. In addition, the interest in inserting algae as one of the additives present in animal feed has been growing, mainly because they are a natural source of biomass and easily cultivated, enhancing performance and animal health [12-15].

Among the algae, Spirulina platensis (Arthrospira platensis) stands out, a blue-green, unicellular alga with nutraceutical, probiotic, antioxidant, anti-inflammatory, hypolipidemic, hypoglycemic, antihypertensive, and immunomodulatory properties [16-18]. Spirulina has been shown to be an efficient dietary supplement for weight control in animals and humans, due to its excellent nutritional profile and the large amount of protein elements, phycocyanin, carotenoids, and all important amino acids for the body's balance [19-22].

In recent years, our research group has studied the various effects of food supplementation with S. platensis, showing that the algae were able to decrease lipid peroxidation and inhibit oxidation in the aorta [23], cavernous body [24], and ileum [25] of rats, as well as the concentration of reactive oxygen species and the inflammation induced by the exercise of force [26]. In addition to reducing adipose reserves and restoring intestinal contractile reactivity in Wistar rats fed a high-fat diet for 16 weeks [27].

Therefore, it is important to evaluate the functional changes and the deleterious effects caused by the consumption of the high calorie diet on parameters related to experimental obesity and intestinal reactivity and the possible therapeutic role of food supplementation with S. platensis in preventing changes in reactivity relaxing and contractile ileum of Wistar rats fed for eight weeks on a calorie-rich diet, investigating the possible mechanisms of action involved in such effects.

\section{Materials and Methods}

2.1. Chemicals. Potassium chloride $(\mathrm{KCl})$, calcium chloride $\left(\mathrm{CaCl}_{2}\right)$, magnesium chloride $\left(\mathrm{MgCl}_{2}\right)$, sodium chloride $(\mathrm{NaCl})$, and formaldehyde were purchased from Vetec Química Fina Ltda. (João Pessoa, Brazil). Sodium bicarbonate $\left(\mathrm{NaHCO}_{3}\right)$ and glucose $\left(\mathrm{C}_{6} \mathrm{H}_{12} \mathrm{O}_{6}\right)$ were purchased from Dinâmica (Brazil). Sodium monobasic phosphate
$\left(\mathrm{NaH}_{2} \mathrm{PO}_{4}\right)$, sodium hydroxide $(\mathrm{NaOH})$, and hydrochloric acid $(\mathrm{HCl})$ were purchased from Nuclear (Brazil). These substances, except glucose, $\mathrm{NaCl}$, and $\mathrm{NaHCO}_{3}$, were diluted in distilled water to obtain each solution, which were maintained under refrigeration.

Carbamylcholine hydrochloride (CCh) was purchased from Merck (USA). Cremophor ${ }^{\circledR}$, thiobarbituric acid, tetramethoxypropane, perchloric acid, Mayer's hematoxylin, and eosin were acquired from Sigma-Aldrich (Brazil). All substances were diluted in distilled water as needed for each experimental protocol. The carbogen mixture $\left(95 \% \mathrm{O}_{2}\right.$ and $5 \% \mathrm{CO}_{2}$ ) was obtained from White Martins (Brazil).

2.2. Animals. Wistar male rats (Rattus norvegicus), 2 months old (approximately $170 \mathrm{~g}$ ), were obtained from the Animal Production Unit (UPA) of the Research Institute for Drugs and Medicines, João Pessoa, Brazil (IpeFarM/UFPB). The animals were maintained under controlled ventilation and temperature $\left(21 \pm 1^{\circ} \mathrm{C}\right)$ with water ad libitum in a $12 \mathrm{~h}$ light-dark cycle (light on from 6 to $18 \mathrm{~h}$ ). The experimental procedures were performed following the principles of guidelines for the ethical use of animals in applied etiology studies [28] and from the Conselho Nacional de Controle de Experimentação Animal of Brazil [29] and were previously approved by the Ethics Committee on Animal Use of UFPB with certificate number 6061090318 .

The animals were randomly divided into three groups (8 rats/group): rats given a standard diet (SD), rats fed a hypercaloric diet (HCD), and fed a hypercaloric diet and simultaneously supplemented with $25 \mathrm{mg} / \mathrm{kg}$ Spirulina platensis for 8 weeks $(\mathrm{HCD}+\mathrm{SP} 25)$. The experimental groups were fed for 8 weeks. After this period, the animals were anesthetized with thiopental sodium ( $100 \mathrm{mg} / \mathrm{kg}$ body weight) mixed with lidocaine $(10 \mathrm{mg} / \mathrm{mL})$, then euthanized by decapitated by guillotine.

2.3. Preparation and Supplementation with Spirulina platensis. Spirulina platensis (Arthrospira platensis) was obtained from the INFINITY Pharma laboratory (HONG KONG, China) (lot No. 20130320), in powder form, and a sample was analyzed, fractionated, and distributed by the Roval Manipulation Pharmacy (João Pessoa, Paraíba, Brazil) (lot No. 405894) to certify that S. platensis lyophilized powder has been obtained.

The S. platensis powder was dissolved in saline solution $(\mathrm{NaCl} 0.9 \%)$ to prepare the dose of $25 \mathrm{mg} / \mathrm{kg}$. The groups supplemented with $25 \mathrm{mg} / \mathrm{kg}$ received the supplementation for a period of 8 weeks [30]. Oral administration was done daily through stainless steel needles for gavage and $5 \mathrm{~mL}$ syringes with a precision of $0.2 \mathrm{~mL}$, between 12 and 14 hours.

2.4. Food Diets. The standard diet (Presence ${ }^{\circledR}$ ) contains $23 \%$ protein, $63 \%$ carbohydrate, and $4 \%$ lipids with $3.8 \mathrm{kcal}$ energy density/g; the hypercaloric diet consisted of standard diet (Presence ${ }^{\circledR}$ ), milk chocolate, peanuts, and sweet biscuits at a ratio of $3: 2: 2: 1$ [31]. The hypercaloric diet contains $23 \%$ protein, $45 \%$ carbohydrate, and 16\% lipids with energy density $4.17 \mathrm{kcal} / 100 \mathrm{~g}$ by weight; this diet was prepared weekly and fed to the animals as granules $[32,33]$ (Table 1). To 
TABLE 1: Macronutrients and caloric value of standard and hypercaloric diets.

\begin{tabular}{lcccc}
\hline Diets & $\begin{array}{c}\text { Carbohydrates } \\
(\%)\end{array}$ & $\begin{array}{c}\text { Proteins } \\
(\%)\end{array}$ & $\begin{array}{c}\text { Lipids } \\
(\%)\end{array}$ & $\begin{array}{c}\text { Total energy } \\
\text { value } \\
(\mathrm{kcal} / 100 \mathrm{~g})\end{array}$ \\
\hline Standard & 63 & 23 & 4 & 3800 \\
Hypercaloric & 45.53 & 22.76 & 16 & 4170 \\
\hline
\end{tabular}

Souza et al. [32].

prepare the hypercaloric diet, the feed, peanuts, and biscuits were ground and mixed, and the chocolate melted in a water bath and added to the mixture to form a homogeneous material that was molded and then dried in an oven $\left(70^{\circ} \mathrm{C}\right)$ for $24 \mathrm{~h}$ and stored at room temperature (Table 1 ). The diet was prepared weekly and offered to rats in the form of pellets [30].

2.5. Ileum Isolation. All animals were fasted for 12 hours before being euthanized. After this period, the rats were anesthetized with ketamine $100 \mathrm{mg} / \mathrm{kg}$ (i.p.) and xylazine $10 \mathrm{mg} / \mathrm{kg}$ (i.p.), and the euthanasia process was completed by decapitation in a guillotine. Then, an abdominal incision was made, and the ileum segment was removed and placed in a Petri dish containing the Krebs Henseleit solution at $37^{\circ} \mathrm{C}$ under aeration with carbogen.

Record isometric contractions, the adjacent connective and adipose tissues of the ileum were removed, and ileum segments $(2-3 \mathrm{~cm})$ were suspended in bath tubs for isolated organs $(6 \mathrm{~mL})$ containing Krebs Henseleit solution aerated with carbogen at $37^{\circ} \mathrm{C}$ and remained at rest under tension of $1 \mathrm{~g}$ for 30 minutes, the time necessary for the stabilization of the organ. During the stabilization period, the nutrient solution was changed every 10 minutes to avoid the interference of metabolites [34].

The physiological solution of Tyrode was used and has the composition as follows (in $\mathrm{mM}$ ): $\mathrm{NaCl}$ (150.0), $\mathrm{KCl}$ (2.7), $\mathrm{CaCl}_{2}$ (1.8), $\mathrm{MgCl}_{2}$ (2.0), $\mathrm{NaHCO}_{3}$ (12.0), $\mathrm{NaH}_{2} \mathrm{PO}_{4}$ (0.4), and D-glucose (5.5). The $\mathrm{pH}$ was adjusted to 7.4, and the ileum was stabilized for $1 \mathrm{~h}$ under a resting tension of $1 \mathrm{~g}$ at $37^{\circ} \mathrm{C}$ and bubbled with a carbogen mixture $[33,34]$.

\subsection{Parameters of Experimental Obesity}

2.6.1. Murinometric Parameters. On the day of euthanasia, the rats were weighed, and the nasoanal length $(\mathrm{cm})$ was used, which was used to calculate the Lee index, from the ratio between the cube root of body mass (g) and the nasoanal length $(\mathrm{cm})$ of the animal [35]. The body mass index (BMI) was calculated from the ratio between body mass (g) and the square of body length $\left(\mathrm{cm}^{2}\right)$ [36]. The abdominal circumference, located in the anterior part of the animal's rear paw, and the thoracic circumference, located in the posterior portion of the front paw, were measured using an anthropometric body measuring tape [36].

2.6.2. Mass of Adipose Tissue Deposits. Twenty-four hours after the last exposure of the diet and supplementation, the rats were euthanized by guillotine, and after careful dissec- tion, the epididymal, retroperitoneal, and inguinal adipose tissues were weighed, which represent the main components of central adiposity in rats [37]. The abdominal fat located in the lower abdomen connected to the epididymis represents the epididymal fat. The fat connected to the posterior abdominal wall around the kidneys and the abdominal part of the ureter represents the retroperitoneal fat. The subcutaneous fat that is located between the lower portion of the rib cage and the median portion of the thigh represents the inguinal fat $[38,39]$.

2.6.3. Adiposity Index. The adiposity index was calculated from the sum of the individual masses of the epididymal, retroperitoneal, and inguinal fat layers, using the following formula: (epididymal fat + retroperitoneal fat + inguinal fat $) \times$ 100/final body mass [40, 41].

2.7. Relaxation Reactivity Measurement. After the stabilization period, a contraction was induced with $25 \mathrm{mM} \mathrm{KCl}$ to check the organ's functionality. Then, the preparation was washed, and a new contraction was induced with $25 \mathrm{mM}$ $\mathrm{KCl}$, and under the tonic component of this contraction was added verapamil $\left(10^{-16}\right.$ to $\left.3 \times 10^{-7} \mathrm{M}\right)$, a blocker of calcium channels dependent on voltage, cumulatively to the vat, in all preparations [42]. The results were evaluated by comparing the responses of the control groups supplemented with saline, obese supplemented with saline, and obese supplemented with $\mathrm{S}$. platensis $(25 \mathrm{mg} / \mathrm{kg})$, and the values of $E_{\max }$ and $\mathrm{pCE}_{50}$ were evaluated as parameters of efficacy and potency, respectively. The values of $E_{\max }$ and $\mathrm{pCE}_{50}$ were obtained by nonlinear regression.

2.8. Contraction Reactivity Measurement. After the stabilization period, the ileum was contracted with $25 \mathrm{mM} \mathrm{KCl}$ to check the integrity of the organ; then, the organ was washed, and after returning to baseline, atropine was preincubated $\left(10^{-6}\right.$ and $\left.10^{-5}\right)[43,44]$, a nonselective antagonist of muscarinic receptors. Subsequently, a cumulative replenished concentration curve for carbacol, an analogue of acetylcholine, was performed. The results were evaluated by comparing the responses of the control groups supplemented with saline (SD and HCD) and supplemented with S. platensis $(\mathrm{HCD}+\mathrm{SP} 25)$, and the values of $E_{\max }$ and $\mathrm{pCE}_{50}$ were evaluated as parameters of efficacy and potency, respectively.

2.9. Ileal Histological and Morphometric Analysis. For a general analysis of the histoarchitecture of the analyzed tissues, the samples were placed in an automatic tissue processor, embedded in paraffin and then cut in a $4 \mu \mathrm{m}$ microtome, placed on histological slides and deparaffinized in xylene for 30 minutes, hydrated in alcohols in decreasing concentrations for 25 minutes and washed in running water for 5 minutes, and then washed in distilled water. The samples were then treated with Harris hematoxylin for 1 minute, washed again in distilled water for 5 minutes and again stained with eosin for 3 minutes, and later washed in running water for another 30 seconds. Finally, the slides were dehydrated in increasing concentrations of alcohols, cleared in xylene, and mounted with Entellan ${ }^{\circledR}$. 


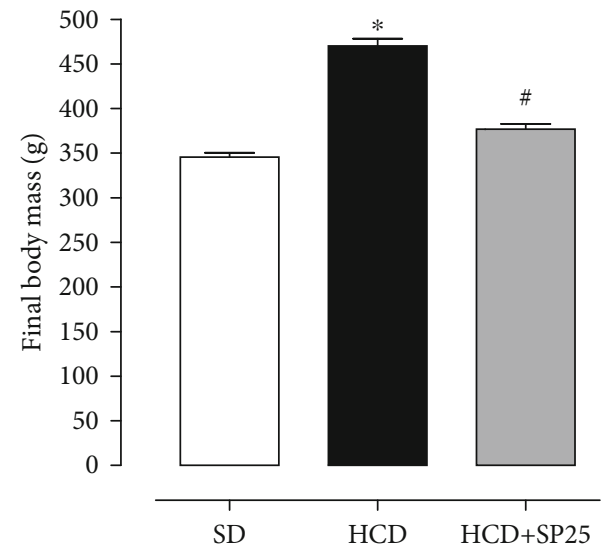

(a)

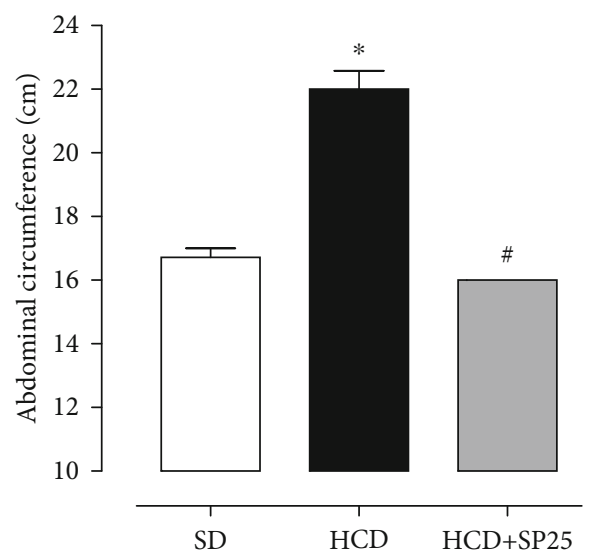

(c)

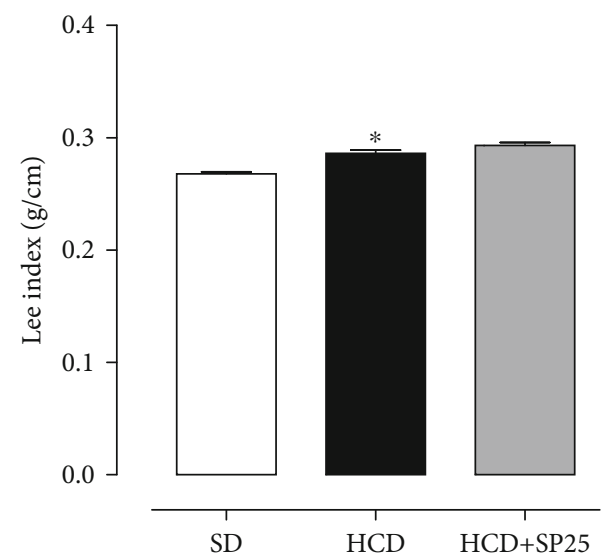

(e)

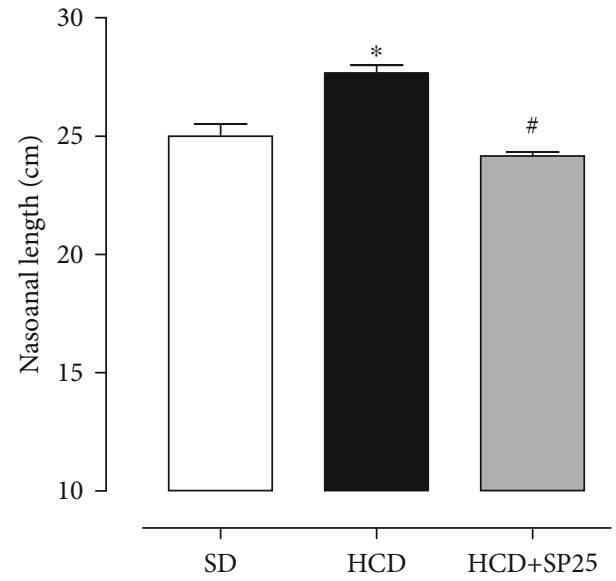

(b)

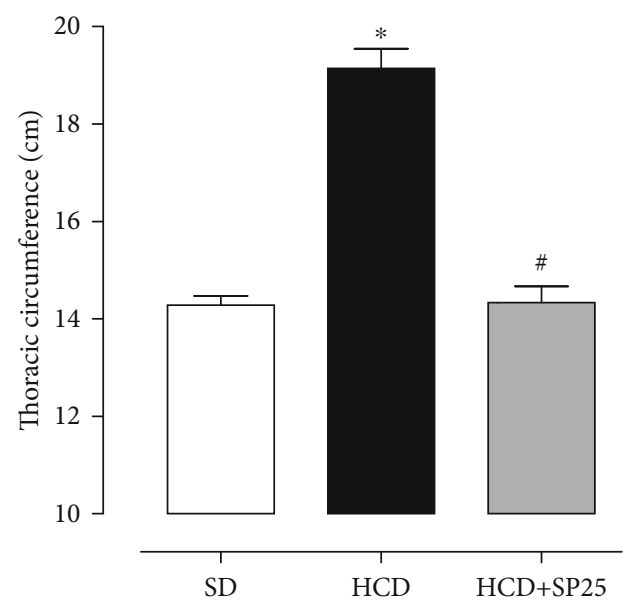

(d)

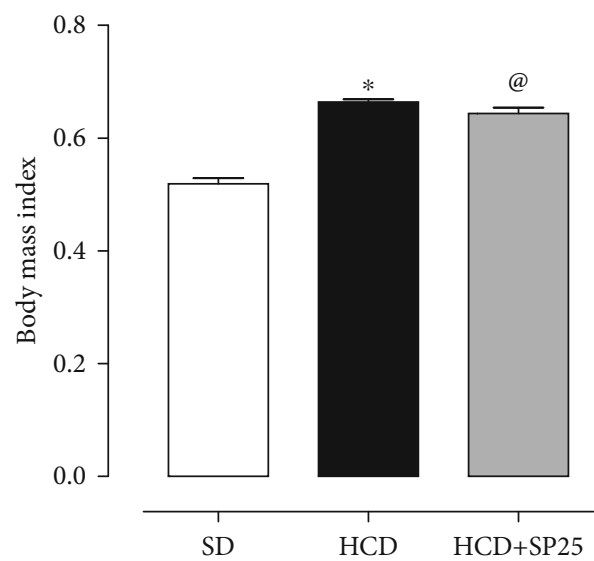

(f)

Figure 1: Continued 


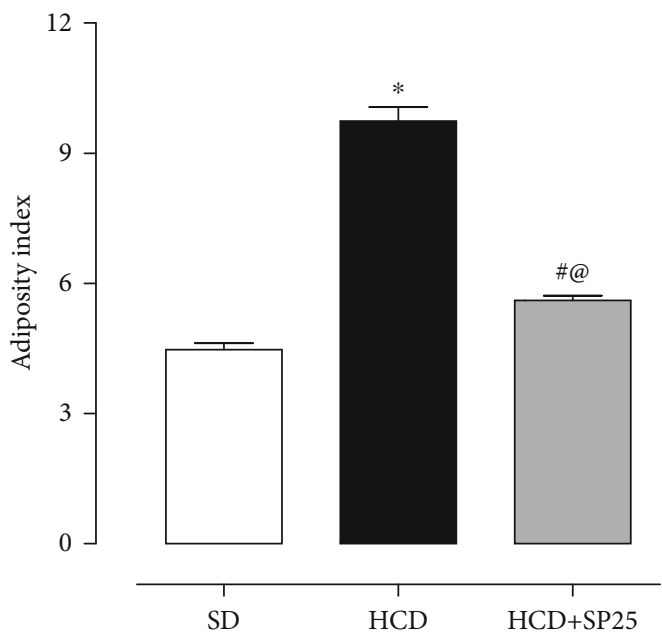

(g)

FIGURE 1: Values of final body mass (a), nasoanal length (b), waist circumference (c), chest circumference (d), Lee index (e), body mass index (f), and adiposity index (g) in rats from group DS, HCD, and HCD + SP25. Columns and vertical bars represent the mean and S.E.M., respectively $(n=5)$. ANOVA was one-way followed by Tukey's posttest. ${ }^{*} p<0.05$ (SD vs. HCD); ${ }^{*} p<0.05(\mathrm{HCD}$ vs. HCD + SP25); ${ }^{\circledR} p<0.05$ (SD vs. HCD + SP25). SD: standard diet group supplemented with saline; HCD: hypercaloric diet group supplemented with saline; HCD + SP25: hypercaloric diet group and supplemented with S. platensis at a dose of $25 \mathrm{mg} / \mathrm{kg}$.

\section{Statistical Analysis}

The results were expressed as mean and standard error of the mean, being analyzed statistically using the $t$-test (unpaired) or the analysis of variance (ANOVA) one way followed by the Tukey posttest. The null hypothesis was rejected when $p$ value $<0.05$. As a power parameter, $\mathrm{pCE}_{50}$ values were used; calculated by nonlinear regression and as an efficiency parameter, $E_{\max }$ was used [45]. All data were analyzed using the GraphPad Prism ${ }^{\circledR}$ program version 6.01 (GraphPad Software Inc., San Diego, CA, USA).

\section{Results}

4.1. Effect of Hypercaloric Diet and Supplementation with S. platensis on Final Body Mass and Murinometric Parameters. In rats fed the hypercaloric diet, an increase in final body mass $(470.1 \pm 8.2 \mathrm{~g})$ was observed when compared to rats fed the standard diet $(345.7 \pm 4.7 \mathrm{~g})$. The rats fed the hypercaloric diet and supplemented with S. platensis at a dose of $25 \mathrm{mg} / \mathrm{kg}(376.7 \pm 5.9)$ showed an increase in body mass when compared to the SD group and a decrease in relation to the HCD group (Figure 1(a)).

When analyzing murinometric parameters, the DHC group had both nasoanal $(27.67 \pm 0.3 \mathrm{~cm})$ and abdominal $(22.0 \pm 0.6 \mathrm{~cm})$ and thoracic $(19.14 \pm 0.4 \mathrm{~cm})$ length difference in relation to the SD group $(25.0 \pm 0.5 \mathrm{~cm}, 16.71 \pm 0.3$ $\mathrm{cm}$, and $14.29 \pm 0.2 \mathrm{~cm}$, respectively). Analyzing the HCD + SP25 group, it had nasoanal length $(24.17 \pm 0.2 \mathrm{~cm})$, lower abdominal $(16.00 \pm 0.1 \mathrm{~cm})$, and thoracic $(5 \mathrm{~cm})$ circumferences when compared to the group HCD and with no difference with the SD group (Figures 1(b)-1(d)).

Regarding the Lee index, the HCD group $(0.817 \pm 0.003$ $\mathrm{g} / \mathrm{cm})$ was higher than the SD $(0.72 \pm 0.01 \mathrm{~g} / \mathrm{cm})$ (Figure 1(e)). In the body mass index (BMI), the HCD group
$(0.66 \pm 0.010)$ showed an increase in relation to the SD group $(0.52 \pm 0.01)$, but the HCD + SP2 5 group $(0.64 \pm 0.01)$ did not differ from the HCD group, showing a difference only when compared to the SD control group (Figure 1(f)). As for the adiposity index, both the HCD group $(9.74 \pm 0.33)$ and the HCD + SP25 group $(5.61 \pm 0.11)$ showed an increase in relation to the SD group $(4.47 \pm 0.15)$. The HCD + SP25 group, when compared to the obese group, had a lower adiposity index $(5.61 \pm 0.11)$ (Figure $1(\mathrm{~g})$ ).

4.2. Effect of Consumption of the Hypercaloric Diet and Food Supplementation with S. platensis on the Mass of Adipose Tissue Deposits. Analyzing the mass of adipose tissue deposits, it was possible to observe that the HCD group rats showed an increase in retroperitoneal $(23.16 \pm 1.0 \mathrm{~g})$, epididymal $(12.76 \pm 0.4 \mathrm{~g})$, and inguinal $(10.4 \pm 1.1 \mathrm{~g})$ when compared to the SD group $(6.05 \pm 0.4 \mathrm{~g}, 4.94 \pm 0.4 \mathrm{~g}$, and $3.92 \pm 0.3 \mathrm{~g}$, respectively) (Figures $2(\mathrm{a})-2(\mathrm{c})$ ). However, the group fed a hypercaloric diet and supplemented with $25 \mathrm{mg} / \mathrm{kg} \mathrm{S}$. platensis observed in the retroperitoneal adipose tissues (10.32 $\pm 0.7 \mathrm{~g})$, epididymal $(6.22 \pm 0.3 \mathrm{~g})$, and inguinal $(13.76 \pm 0.2 \mathrm{~g})$ relative decrease in fat deposition when compared to the obese HCD group, with no significant difference in SD (Figures 2(a)-2(c)).

4.3. Effect of Consumption of the Hypercaloric Diet and Food Supplementation with S. platensis on the Relaxing Reactivity of Isolated Rat Ileum. In the HCD group, a decreased $\mathrm{KCl}$ contractile power was observed in the presence of verapamil $\left(\mathrm{pCE}_{50}=6.09 \pm 0.21\right)$ when compared to the group that consumed only the standard diet $\left(\mathrm{pCE}_{50}=10.90 \pm 0.52\right)$. In addition, it can be observed that there were no changes regarding the relaxing potency of verapamil between the $\mathrm{HCD}+\mathrm{SP} 25$ group $\left(\mathrm{pCE}_{50}=10.55 \pm 0.33\right)$ and SD; however, 


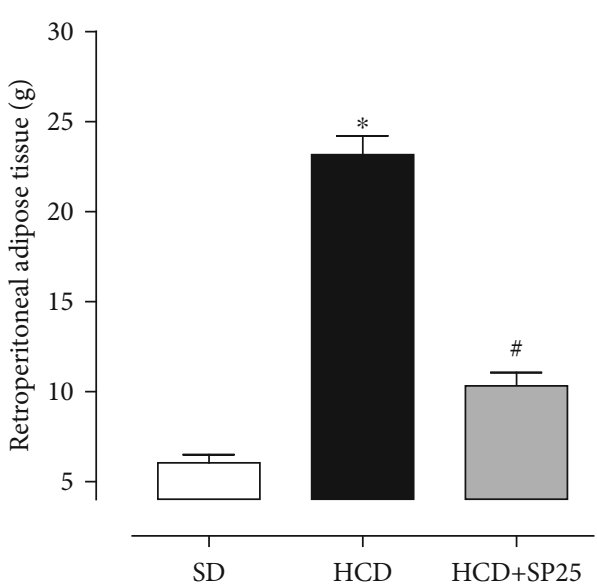

(a)

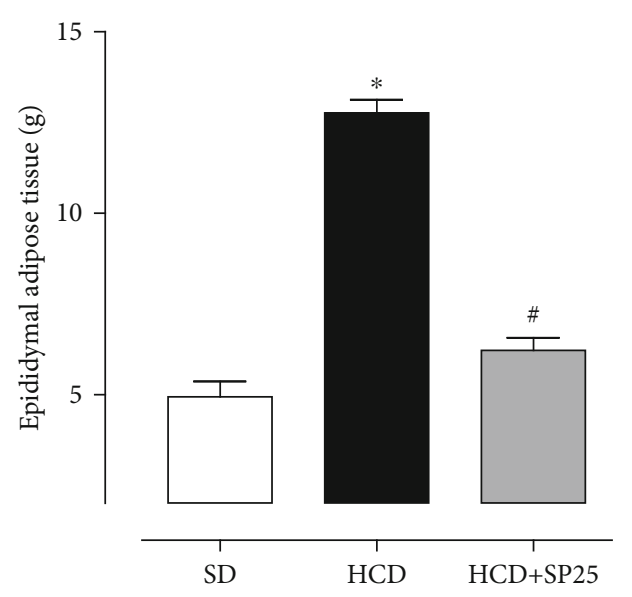

(b)

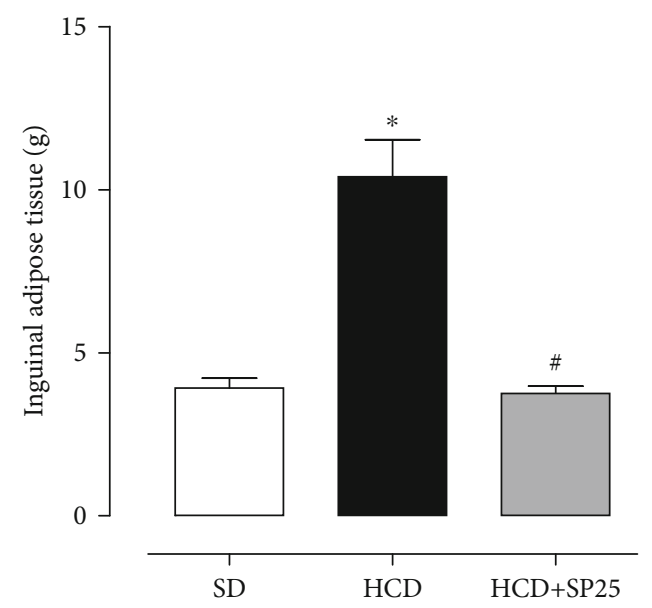

(c)

FIGURE 2: Values of the masses of adipose tissue deposits: retroperitoneal (a), epididymal (b), and inguinal (c) in rats from groups SD, HCD, and HCD + SP25. Columns and vertical bars represent the mean and S.E.M., respectively $(n=5)$. ANOVA was one-way followed by Tukey's posttest. ${ }^{*} p<0.05$ (SD vs. HCD); ${ }^{\#} p<0.05$ (HCD vs. HCD + SP25); ${ }^{\circledR} p<0.05$ (SD vs. HCD + SP25), $(n=5)$. SD: standard diet group supplemented with saline; HCD: hypercaloric diet group supplemented with saline; HCD + SP25: hypercaloric diet group and supplemented with S. platensis at a dose of $25 \mathrm{mg} / \mathrm{kg}$.

it is possible to verify an increase in power when compared to the HCD group (Figure 3).

4.4. Effect of Consumption of the Hypercaloric Diet and Food Supplementation with S. platensis on the Cumulative Curve of Contraction Induced by Carbachol in the Absence and Presence of Atropine in the Groups Fed the Standard Diet. In the presence of $10^{-6} \mathrm{M}$ atropine, it was observed that the cumulative contraction curve for $\mathrm{CCh}$ shifted to the right with an increase in $\mathrm{pCE}_{50}(3.5 \pm 0.2)$ when compared to the contraction curve in the absence of the antagonist $(6.3 \pm 0.04)$ without changing $E_{\max }(100 \%)$. Similar results were observed in the presence of $10^{-5} \mathrm{M}$ atropine, in which the CCh contraction curve was shifted to the right, with an increase in $\mathrm{pCE}_{50}(2.3 \pm 0.01)$ without changing $E_{\max }(100 \%)$.

4.5. Effect of Consumption of the Hypercaloric Diet and Food Supplementation with S. platensis on the Cumulative Curve of Contraction Induced by Carbachol in the Absence and Presence of Atropine in the Groups Fed the Hypercaloric
Diet. In the group fed during the eight weeks with the hypercaloric diet, a decrease in the maximum effect was observed $(32.0 \pm 2.9)$ when compared to the contraction curve of the group of animals that were fed a standard diet $(6.3 \pm 0.04)$ without changing the $\mathrm{pCE}_{50}(6.6 \pm 0.01$ and $6.3 \pm 0.04$, respectively) (Figure 4 ).

In the HCD group in the presence of $10^{-6} \mathrm{M}$ atropine, it was observed that the cumulative contraction curve in CCh was shifted to the right with an increase in $\mathrm{pCE}_{50}$ $(3.9 \pm 0.08)$ when compared to the contraction curve in the absence of the antagonist in the group HCD $(6.6 \pm 0.01)$ with a change in $E_{\max }(32.0 \pm 2.9$ and $44.6 \pm 2.0 \%$, respectively). Similar results were observed in the presence of $10^{-5} \mathrm{M}$ atropine, in which the CCh contraction curve was shifted to the right, with an increase in pCE50 $(2.9 \pm 0.03)$ with an $E_{\max }$ change $(30.2 \pm 0.9 \%)$ (Figure 4$)$.

4.6. Effect of Consumption of the Hypercaloric Diet and Food Supplementation with S. platensis on the Cumulative Curve of Contraction Induced by Carbachol in the Absence and 


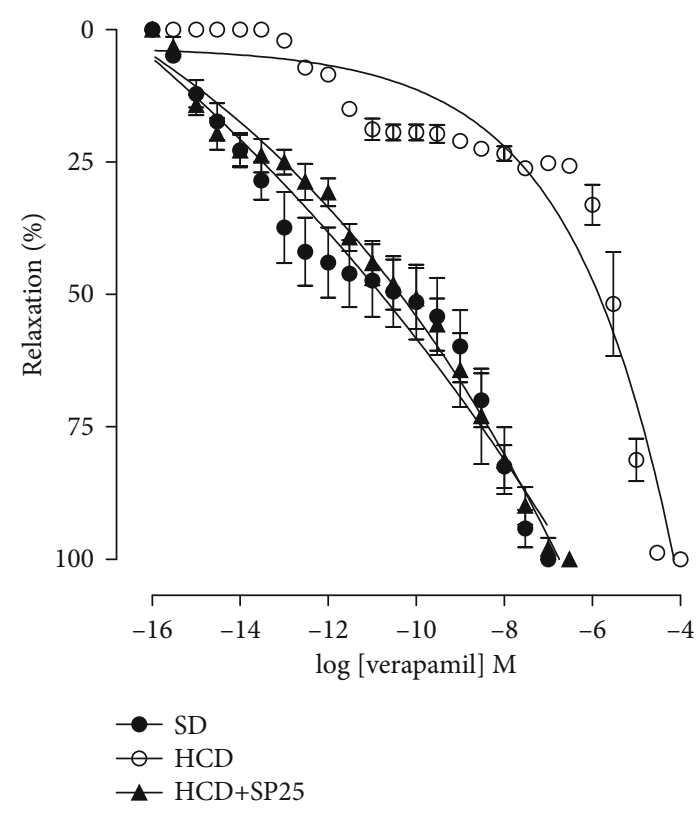

FIgURE 3: Cumulative concentration-response curve for verapamil in rat ileum in the SD (๑), HCD (O), and HCD + SP25 (A) groups. The symbols and vertical bars represent the mean and S.E.M., respectively $(n=5)$. ANOVA was one-way followed by Tukey's posttest. ${ }^{*} p<0.05$ (SD vs. HCD), ${ }^{*} p<0.05$ (HCD vs. $\mathrm{HCD}+\mathrm{SP} 25)$, and ${ }^{@} p<0.05$ (SD vs. DHC + SP25). SD: group fed a standard diet; HCD: group fed a hypercaloric diet; HCD + SP25: groups fed a hypercaloric diet and supplemented with $S$. platensis $25 \mathrm{mg} / \mathrm{kg}$, respectively.

Presence of Atropine in the Groups Fed a Hypercaloric Diet and Supplemented Simultaneously with S. platensis at a Dose of $25 \mathrm{mg} / \mathrm{kg}$. In the group submitted to a hypercaloric diet and supplemented with Spirulina platensis at a dose of $25 \mathrm{mg} / \mathrm{kg}(\mathrm{HCD}+\mathrm{SP} 25)$ in the presence of $10^{-6} \mathrm{M}$ atropine, it was observed that the cumulative contraction curve shifted to the right with decreased potency $\left(\mathrm{pCE}_{50}=3.4 \pm 0.4\right)$ when compared to the contraction curve in the absence of the antagonist in the SD group $\left(\mathrm{pCE}_{50}=6.3 \pm 0.04\right)$ with a change in $\left(E_{\max }=59.89 \pm 1.2\right.$ and $100 \%$, respectively); similar results occurred when compared to the contraction curve in the absence of the antagonist in the $\mathrm{HCD}$ group $\left(\mathrm{pCE}_{50}=6.6 \pm 0.1\right)$ with change in the maximum effect $\left(E_{\max }=59.89 \pm 1.2\right.$ and $32.0 \pm 2.9 \%$, respectively) and when compared to the contraction curve in the absence of the antagonist in the $\mathrm{HCD}+\mathrm{SP} 25$ group $\left(\mathrm{pCE}_{50}=6.2 \pm 0.1\right)$ with change in the maximum effect $\left(E_{\max }=59.89 \pm 1.2\right.$ and $63.87 \pm 1.0 \%$, respectively) (Figure 5 ).

Similar results were observed in the group submitted to a hypercaloric diet and supplemented with Spirulina platensis at a dose of $25 \mathrm{mg} / \mathrm{kg}(\mathrm{HCD}+\mathrm{SP} 25)$ in the presence of $10^{-}$ ${ }^{5} \mathrm{M}$ atropine, in which the CCh contraction curve was shifted to right with decreased contractile force $\left(\mathrm{pCE}_{50}=2.8 \pm 0.3\right)$ with a change in the maximum effect $\left(E_{\max }=47.93 \pm 4.8 \%\right)$ (Figure 5).

4.7. Effect of Hypercaloric Diet and Spirulina platensis Supplementation on Histology and Ileal Morphometry of Rats. In animals in the SD group, it is observed that the

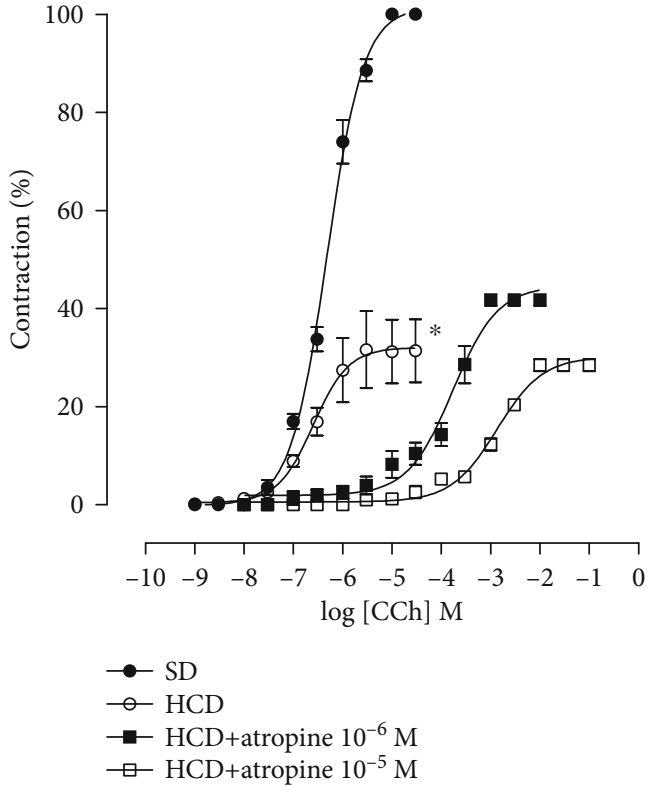

FIGURE 4: Cumulative concentration-response curves on the CCh of the SD (๑), HCD (O), HCD + atropine $10^{-6} \mathrm{M}(\boldsymbol{\square})$, and HCD + atropine $10^{-5} \mathrm{M}(\square)$ groups in isolated rat ileum. The symbols and vertical bars represent the mean and S.E.M., respectively $(n=5)$. ANOVA was one-way followed by Tukey's posttest. ${ }^{*} p<$ 0.05 (SD vs. $\mathrm{HCD}$ ), ${ }^{\#} p<0.05$ ( $\mathrm{HCD}$ vs. $\mathrm{HCD}+$ atropine $10^{-6} \mathrm{M}$ and $10^{-5} \mathrm{M}$ ), and ${ }^{\circledR} p<0.05$ (SD vs. HCD + atropine $10^{-6} \mathrm{M}$ and $10^{-}$ $\left.{ }^{5} \mathrm{M}\right)$. SD: group fed a standard diet; HCD: group fed a hypercaloric diet; HCD + SP25: groups fed a hypercaloric diet and supplemented with $S$. platensis $25 \mathrm{mg} / \mathrm{kg}$, respectively.

mucosa has some mononuclear inflammatory cells, such as macrophages and few plasmocytes, with preservation of goblet cells and enterocytes (Figures 6(a) and 6(d)). In animals in the HCD group, it is observed that the inflammatory infiltrate in the mucosa is extensive and multifocal $(* * *)$, rich in mononuclear cells, such as macrophages and many plasmocytes (Figures 6(b) and 6(e)). In animals from the HCDSP25 group, a slight increase in the number of mononuclear cells $(*)$, with the same phenotype, macrophages, and lymphocytes, is observed in the mucosa (Figures 6(c) and 6(f)).

In the ileal morphometric analysis of the mucosal area, it was observed that the animals in the HCD group (149.9 \pm 1.6 ) had a decrease in the length of the intestinal villi when compared to the SD control group $(166.3 \pm 0.8)$. The HCD + SP 25 group $(164.4 \pm 0.8)$ showed no difference compared to the SD group (Figure 7(a)). Similarly, when analyzing the width of the intestinal villi of the ileum of rats in the HCD group (125.6 \pm 1.2$)$, a decrease was observed in relation to the SD group $(145 \pm 1.0)$. The group supplemented with Spirulina at a dose of $25 \mathrm{mg} / \mathrm{kg}(143 . \pm 2.0)$ also showed no difference when compared to the control group (145 \pm 1.0$)$ (Figure 7(b)).

Likewise, in the morphometric analysis of the outer muscle layer, it was observed that the group fed the high-calorie diet HCD $(81.7 \pm 0.9)$ presented a decrease in the muscle layer compared to the SD group $(98.5 \pm 0.4)$. Interestingly, the ileal muscle layer of the HCD + SP25 group $(90.5 \pm 1.5)$ 


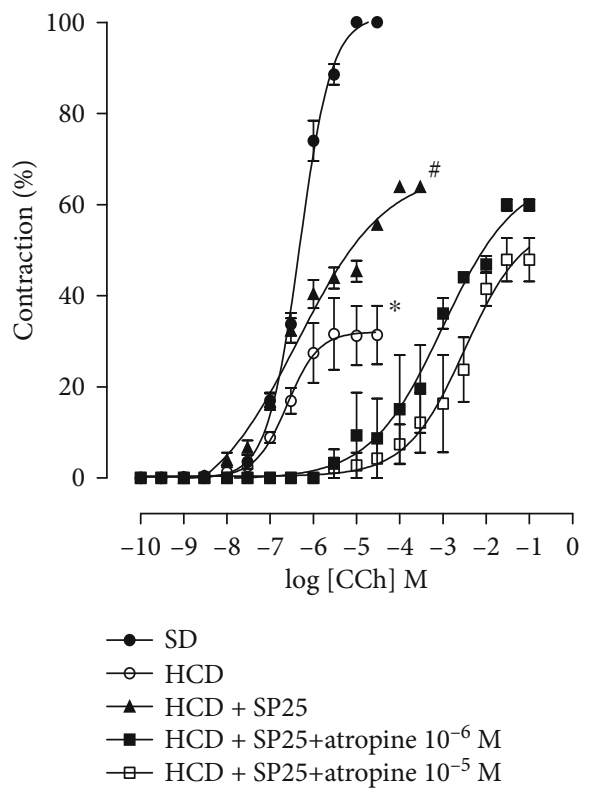

FIGURE 5: Cumulative concentration-response curves on the CCh of

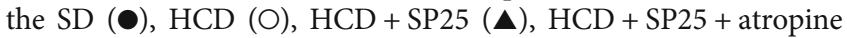
$10^{-6} \mathrm{M}(\boldsymbol{\square})$, and $\mathrm{HCD}+\mathrm{SP} 25+$ atropine $10^{-5} \mathrm{M}(\square)$ groups in isolated rat ileum. The symbols and vertical bars represent the mean and S.E.M., respectively $(n=5)$. ANOVA was one-way followed by Tukey's posttest. ${ }^{*} p<0.05$ (SD vs. HCD), ${ }^{*} p<0.05$ (HCD vs. $\mathrm{HCD}+\mathrm{SP} 25)$, and ${ }^{\circledR} p<0.05$ (HCD + SP25 vs. $\mathrm{HCD}+$ SP25 + atropine $10^{-6} \mathrm{M}$ and $\left.10^{-5} \mathrm{M}\right)$. SD: group fed a standard diet; HCD: group fed a hypercaloric diet; HCD + SP25: groups fed a hypercaloric diet and supplemented with S. platensis $25 \mathrm{mg} / \mathrm{kg}$, respectively.

presented differences in relation to both the HCD $(81.7 \pm 0.9$ ) and SD $(98.5 \pm 0.4)$ groups (Figure $7(\mathrm{c})$ ).

\section{Discussion}

In the present study, the experimental obesity model was induced by consuming a hypercaloric diet in Wistar rats for 8 weeks, which resulted in increased final body mass, murinometric parameters, and body adiposity index, as well as promoting a reduction in relaxing and ileal contractile reactivity. Interestingly, the deleterious effects promoted by the consumption of the hypercaloric diet were prevented by supplementing food with S. platensis.

Obesity for being able to cause comorbidities in individuals is already considered a serious public health problem [46]. Thus, to better understand the effects and mechanisms that the disease brings to, the individual, hypercaloric diets are used to induce a state of experimental obesity in rats, mimicking the consequences that they would bring to humans [47]. Wistar rats were fed a standard and/or hypercaloric diet for eight weeks and simultaneously received saline solution and/or supplementation with $S$. platensis at a dose of $25 \mathrm{mg} / \mathrm{kg} /$ day, based on the principle that in previous studies, carried out by our research group, this was the dose that had the best effects [48].

When analyzing the data related to experimental obesity, it is possible to observe that the rats fed with the hypercaloric diet had an increase in the final body mass and that the supplementation with Spirulina platensis at a dose of $25 \mathrm{mg} / \mathrm{kg}$ totally prevented this increase, not having a significant difference when compared to the control group fed a standard diet (Figure 1(a)). Such results suggest that the consumption of the hypercaloric diet was effective in increasing the final body mass, consequently favoring the onset of obesity in these animals. In addition, the protective effect attributed to kelp can be related to its composition and properties, characterized by a high content of proteins (approximately $70 \%$ ), bioactive compounds, and antioxidants, which contribute to the thermogenesis process and decrease lipogenesis, preventing therefore, the accumulation of lipid and the deposition of fat from consumption of the hypercaloric diet $[49,50]$.

To verify the effectiveness of the hypercaloric diet in the development of obesity as well as the possible protective role of supplementation with $S$. platensis, parameters related to experimental obesity were evaluated (Lee index, BMI, adiposity, nasoanal length, measured abdominal and thoracic circumference, and mass of fat reserves). From these results, it is possible to infer the evidence of the onset of obesity from the hypercaloric diet used in this study. Additionally, dietary supplementation with algae at a dose of $25 \mathrm{mg} / \mathrm{kg}$ was effective in partially and/or totally preventing some of the analyzed parameters (Figures $1(\mathrm{~b})-1(\mathrm{~d})$ and $1(\mathrm{~g})$ ), thus reaffirming its antiobesity effects. However, no differences were observed between the Lee index and the BMI of the experimental groups (Figures 1(e) and 1(f)), similar to that observed in different studies with animal obesity induced by excessive intake of sucrose $(300 \mathrm{~g} / \mathrm{L})$ or lipids ( $42.9 \%$ lipids per kcal) $[51,52]$.

In animals, mainly rats, fat deposition occurs predominantly in three distinct regions; these reserves are located in the retroperitoneal, epididymal, and inguinal adipose tissues. The assessment of the mass of these regions helps to determine the physiological dysfunctions resulting from the ingestion of hyperlipidic and/or hypercaloric diets [53-55]. Thus, it was observed that the obese rats showed an increase in adipose, retroperitoneal (Figure 2(a)), epididymal (Figure 2(b)), and inguinal (Figure 2(c)) deposits and that food supplementation with S. platensis was able to prevent this increase in all of them. Furthermore, based on these results, a possible modulating activity of $S$. platensis in preventing and reducing adipose deposits of rats fed a hypercaloric diet is demonstrated.

Once the development of obesity and the physiological changes caused by the consumption of the hypercaloric diet were confirmed and that supplementation with $S$. platensis prevented such dysfunction, the investigation of the impact of diet and supplementation with algae on relaxing reactivity was continued intestinal, since the increase in body adiposity is associated with decreased relaxing reactivity in ileum of Wistar rats, and food supplementation with S. platensis at a dose of $50 \mathrm{mg} / \mathrm{kg}$ was able to reverse these changes [27].

In this study, it was demonstrated that the hypercaloric diet decreased the ileal relaxing reactivity, confirmed by the decrease in the relaxing efficacy of verapamil (Figure 8), making this relaxation difficult. In addition, supplementation with $S$. platensis completely prevented the decrease in both the potency and the relaxing effectiveness of the 


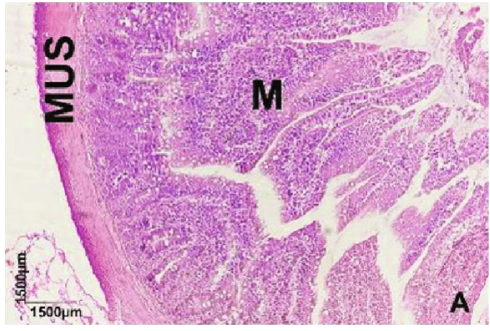

(a)

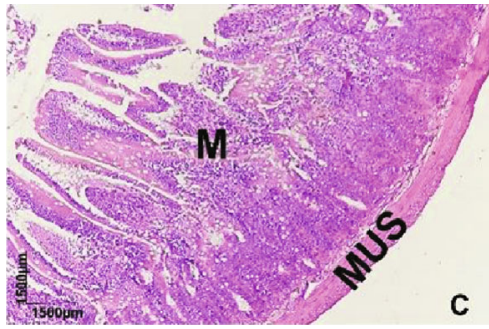

(c)

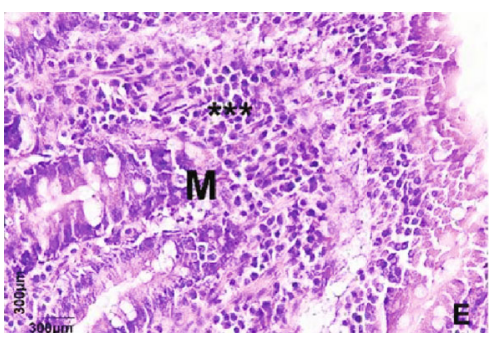

(e)

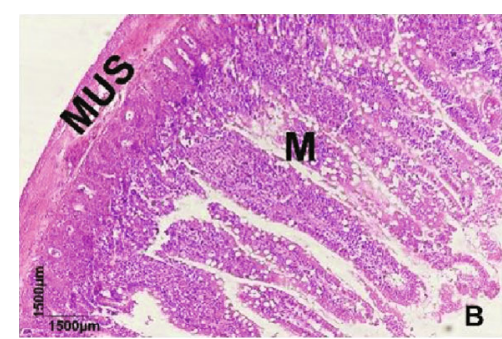

(b)

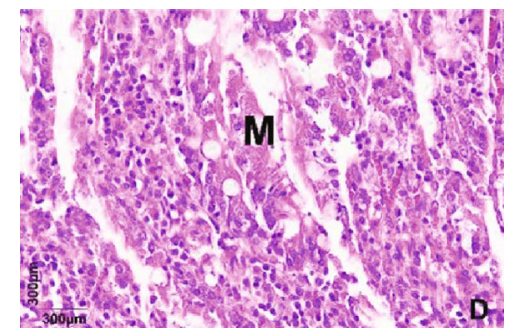

(d)

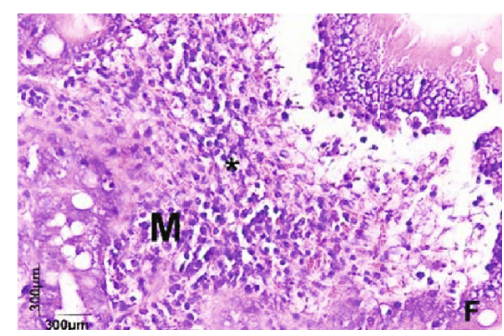

(f)

FIgURE 6: Histological section of rat ileum stained in hematoxylin and eosin showing parts of the organ, highlighting the mucosa (M) and the external muscle (MUS). Panoramic view $(\mathrm{a}-\mathrm{c})$ and higher magnification $(\mathrm{d}-\mathrm{f})$ showing histological images of the ileum of rats from SD, HCD, and HCD + SP25 groups, respectively.

electromechanical component, bringing them back to what was observed in the control group, confirmed by the overlapping curves. Likewise, the hypercaloric diet reduced the contractile effectiveness of $\mathrm{KCl}$, proving that it reduces the contractions caused by electromechanical coupling [33]. In contrast, Ferreira [27] did not observe any difference between animals fed a standard diet supplemented with S. platensis in relation to the obese group, and it is not possible to observe a reversal of such effects. However, our study demonstrated that food supplementation with S. platensis at a dose of $25 \mathrm{mg} / \mathrm{kg}$ prevented changes caused by the high calorie diet, thus inferring that algae may be a possible alternative for the prevention of intestinal diseases in obese people.

Studies have shown that obesity increases vasoconstriction in the aorta of obese rats, in which possibly the excessive accumulation of adipose tissue is related to increasing the expression of proteins in the calcium sensitization pathway [56] and therefore decreasing the potency of ileal relaxants, and it may be suggested that this effect is associated with a decrease in the expression of voltage-gated calcium channels $\left(\mathrm{Ca}_{\mathrm{V}}\right)[57,58]$. Consequently, $S$. platensis may be preventing the decrease in calcium influx, improving changes in intestinal reactivity. Thus, to validate this hypothesis, there is a need for investigative studies on the participation of these channels in the ileum of obese rats supplemented with S. platensis.
Once all these deleterious damages resulting from the consumption of the hypercaloric diet were verified, and as in previous studies, it was observed that the consumption of this diet is directly related to the increase in contractile reactivity and reduction in the relaxing response of various organs in rats $[24,59,60]$; it was decided to investigate the mechanism of action by which the ingestion of the hypercaloric diet promotes a reduction in the contractile reactivity of the ileum [48], effects that were prevented in rats fed the hypercaloric diet by supplemental feeding with $S$. platensis.

The intestinal contractile reactivity was evaluated using as a premise the property that the intestinal smooth muscle has to undergo actions mediated by acetylcholine $(\mathrm{ACh})$, which when it binds to its muscarinic receptor type $M_{3}$, highly expressed in this musculature, triggers contractile responses [61]. Thus, to mimic the pharmacological action of this hormone, carbachol, an agonist of ACh muscarinic receptors, resistant to degradation by acetylcholinesterase, was used to assess the pharmacomechanical coupling of ileum contraction in Wistar rats [62].

Recently, Souza et al. [33] found that Wistar rats fed for 8 weeks on a hypercaloric diet showed reduced intestinal contractile efficacy compared to $\mathrm{KCl}$ and $\mathrm{CCh}$. Thus, once the onset of obesity was confirmed and a reduction in ileal contractile reactivity was verified, the hypothesis was raised that 


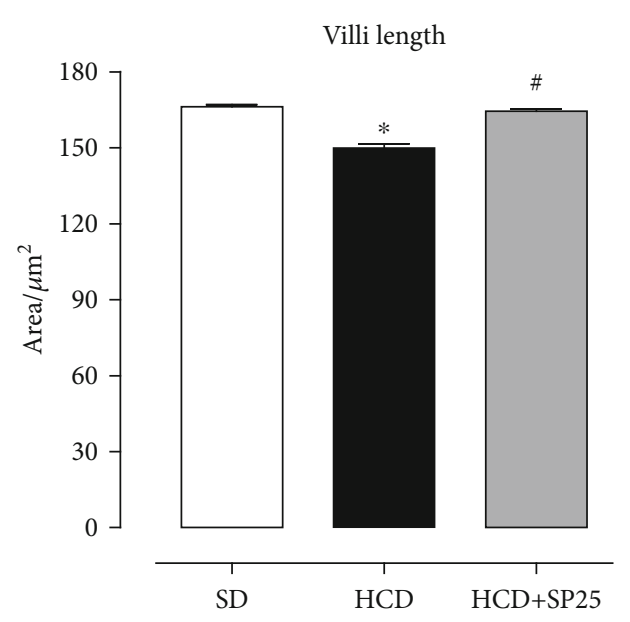

(a)

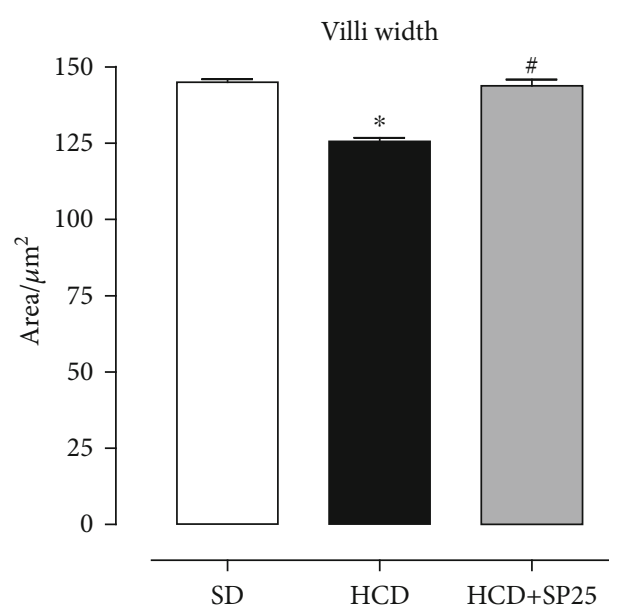

(b)

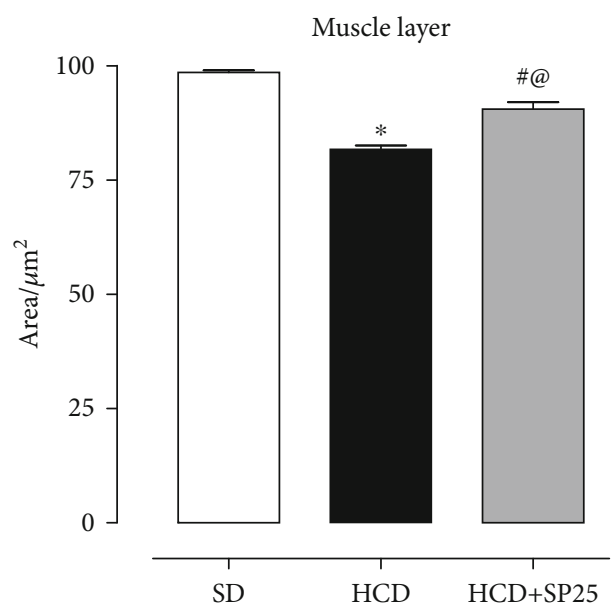

(c)

FIGURE 7: Ileum morphometry showing villi length (a), villi width (b), and muscle layer (c) of groups the SD, HCD, and HCD + SP25. Columns and vertical bars represent the mean and S.E.M., respectively $(n=5)$. ANOVA was one-way followed by Tukey's posttest. ${ }^{*} p<$ 0.05 (SD vs. HCD), ${ }^{\#} p<0.05$ (HCD vs. HCD + SP25), and ${ }^{\circledR} p<0.05$ (HCD + SP25 vs. HCD + SP25). SD: group fed a standard diet; HCD: group fed a hypercaloric diet; HCD + SP25: groups fed a hypercaloric diet and supplemented with S. platensis $25 \mathrm{mg} / \mathrm{kg}$, respectively.

the consumption of the hypercaloric diet could decrease the contractile response to CCh by negatively modulating the muscarinic receptors present in the intestinal smooth muscle and that by its antioxidant role, supplementation could prevent this modulation by possibly acting on calcium influx.

For this, in the group fed a standard diet, atropine $\left(10^{-6}\right.$ and $\left.10^{-5} \mathrm{M}\right)$, an antagonist of muscarinic receptors, was incubated, showing that in both concentrations the cumulative contraction curve to $\mathrm{CCh}$ was shifted to the right with decreased force and no change in the maximum effect (Figure 8). These results were already expected, since atropine is a competitive antagonist of muscarinic receptors, requiring increasing concentrations of carbachol to displace it from the $\mathrm{M}_{3}$ receptor in the ileum to obtain the same contractile effect [63]. However, this protocol is of fundamental importance for the analysis and comparison of the effects and potencies of the maximum amplitudes of the HCD and $\mathrm{HCD}+\mathrm{SP} 25 \mathrm{mg} / \mathrm{kg}$ groups with those of the control group, fed only with a standard diet. It is also possible to observe that the presence of atropine in both concentrations continued to shift the contraction curve to the right without changing the maximum effect, suggesting, therefore, that obesity and/or the hypercaloric diet did not alter the expression of muscarinic receptors, per se.

In this study, it was demonstrated that the consumption of a hypercaloric diet significantly decreased the ileal contractile response to $\mathrm{CCh}$. In the HCD group in the presence of $10^{-6}$ and $10^{-5} \mathrm{M}$ atropine, it was observed that the cumulative contraction curves of the CCh shifted to the right with decreased contractile force, with a change in the maximum effect (Figure 4). This decrease in ileal contractile reactivity does not involve the participation of muscarinic receptors, possibly being associated with modulation of the $\mathrm{Ca}_{\mathrm{V}}$ and/or related to mechanisms involving the antioxidant system, mainly due to the increased expression of malondialdehyde (MDA), the main product of lipid peroxidation, corroborating the findings of previous studies by our research group [27, 33].

Previous studies carried out by our research group showed that food supplementation with the alga S. platensis 


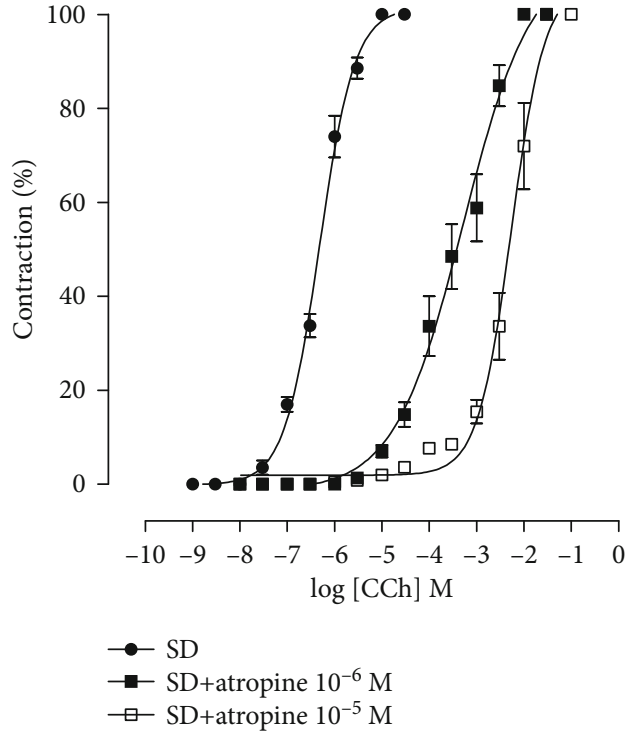

FIGURE 8: Cumulative concentration-response curves for the CCh of the SD (•), SD + atropine $10^{-6} \mathrm{M}(\boldsymbol{\square})$, and SD + atropine $10^{-5} \mathrm{M}(\square)$ groups in isolated rat ileum. The symbols and vertical bars represent the mean and S.E.M., respectively $(n=5)$. ANOVA was one-way followed by Tukey's posttest. ${ }^{*} p<0.05$ (SD vs. HCD), ${ }^{*} p<0.05$ (HCD vs. HCD + SP25), and ${ }^{\circledR} p<0.05$ (SD vs. HCD + SP25). SD: group fed a standard diet; HCD: group fed a hypercaloric diet; HCD + SP25: groups fed a hypercaloric diet and supplemented with $S$. platensis $25 \mathrm{mg} / \mathrm{kg}$, respectively.

was able to improve contractile reactivity in the aorta, avoiding oxidative stress [23] and restoring erectile function in obese rats [24], as well as is related to increased contractile reactivity in the ileum of rats fed a hypercaloric diet [25] by promoting increased bioavailability of nitric oxide.

Additionally, excessive consumption of fats and calories is associated with metabolic and gastrointestinal disorders. Furthermore, animal research has shown that long-term consumption of high-calorie diets is particularly related to damage to the gastrointestinal mucosa $[64,65]$. Thus, intestinal histological and morphometric parameters are very important and used as scientific tools to evidence such findings and particularly the effects of the hypercaloric diet as well as Spirulina platensis on the histomorphology of the ileum of rats have not yet been elucidated.

The intestinal mucosal barrier plays essential roles in preserving intestinal health [66]. Among the components of the intestinal epithelial mucus layer is mucin, synthesized and secreted by goblet cells; this mucus layer is responsible for separating part of the intestinal content from the intestinal epithelial cells, protecting the cells against the invasion of harmful substances and has an active role in regulating mucosal immunity [67-69]. Our results showed that the consumption of the high-calorie diet considerably reduced the number of goblet cells and enterocytes (Figures 6(b) and 6(e)) important for digestion and absorption of nutrients from the diet, which is associated with changes in the intestinal permeability of the intestinal epithelial cell barrier, inducing oxidative stress and apoptosis. Furthermore, the highcalorie diet considerably increased the inflammatory profile

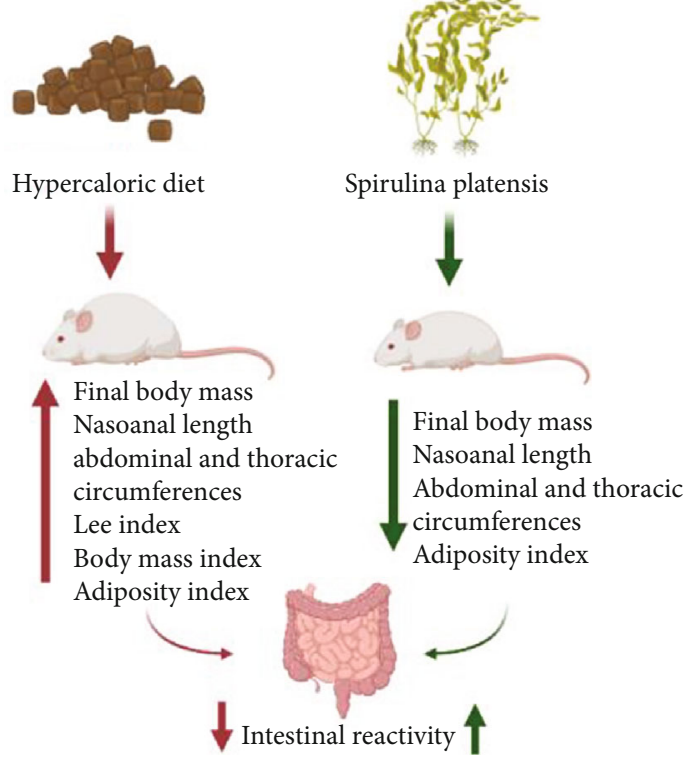

FIgURE 9: The consumption of the hypercaloric diet induces the onset of obesity in rats by increasing all parameters evaluated in this study and consequently leads to a decrease in ileal reactivity. Food supplementation with Spirulina platensis prevents the development of obesity and the reduction of contractile reactives and intestinal relaxants.

of the ileum (Figures 6(b) and 6(e)) observed in the images due to the rich presence of mononuclear cells, specifically macrophages and plasma cells, characteristic of the body's adipose tissue accumulation process (D7, D8). Morphometric analyses of the intestinal mucosa of the ileum confirm the histological results, since it is possible to observe that the length (Figure 7(a)) and width (Figure 7(b)) of the ileum intestinal villi as well as the muscle layer (Figure $7(\mathrm{c})$ ) presented a decrease in relation to the control group.

On the other hand, Spirulina platensis was able to prevent the harmful effects on the ileum mucous layer caused by the consumption of the high-calorie diet, approaching the histological findings of the control group, characterized by a slight increase in the number of mononuclear cells of the same phenotype and number of reduced macrophages and lymphocytes (Figures 6(c) and 6(f)). This effect may be associated with the nutritional composition of the alga, composed of high levels of antioxidants, carotenoids, phycocyanins, and vitamins, in addition to the pharmacological and biological activities already evidenced, which are related to gastropopotetic activities, anti-inflammatory, and antioxidant effects, in addition to increased antioxidant capacity of various organs $[17,68-70]$, which was confirmed by the morphometric analysis of the ileal mucosa in which all parameters evaluated were preserved (Figure 7) and did not distinguish from the healthy control group shown in Figure 7.

In view of these results, it is possible to evidence the effectiveness of the experimental obesity model in promoting damage on the intestinal reactivity of the ileum of Wistar rats and that the supplementation with Spirulina platensis at a dose of $25 \mathrm{mg} / \mathrm{kg}$ was potentially capable of preventing the deleterious effects induced by the consumption of 
hypercaloric diet during the 8-week period. In addition, this research demonstrated the beneficial potential of dietary supplementation with S. platensis in obesity, as well as in the prevention of intestinal disorders associated with reactivity of intestinal smooth muscle, such as diarrhea, constipation, and poor digestion, which may be associated with improvement and prevention of intestinal dysbiosis, very associated with obesity and intake of irregular diets. In view of the popularity of Spirulina platensis consumption as a functional food and its safety already proven, the results of this research and previous works in the literature justify the execution of clinical trials to investigate the possible protective role of this blue-green algae in diseases and intestinal disorders associated with obesity and other inflammatory pathologies.

\section{Conclusion}

Food supplementation with the algae Spirulina platensis, the research star of this study, points to a possible preventive antiobesity role and a protector of deleterious effects and preserving the intestinal histomorphological environment on intestinal reactivity (Figure 9). In addition, the hypercaloric diet decreases contractile reactivity in rat ileum by mechanisms that are related to a downregulation of muscarinic receptors, and dietary supplementation with algae prevents the reduction of intestinal reactivity induced by the consumption of the hypercaloric diet, possibly by modulating the expression positively of the $\mathrm{Ca}_{\mathrm{V}}$. These data suggest the beneficial effects of algae as a potential therapeutic arsenal in the prevention of obesity and associated intestinal diseases, diarrhea, irritable bowel disease, and some types of gastrointestinal cancer.

\section{Data Availability}

The hypothesis and review data used to support the findings of this study are included within the article.

\section{Conflicts of Interest}

The authors declare no conflict of interest.

\section{Acknowledgments}

The authors thank CAPES and CNPq for financial support and UFPB for institutional support. This work was funded by the Conselho Nacional de Desenvolvimento Científico e Tecnológico $(\mathrm{CNPq})$, through a scholarship granted and approved project (protocol 6061090318), and by the Coordenação de Aperfeiçoamento de Pessoal de Nível Superior (CAPES) through support for postgraduate activities in the Program of Academic Excellence (PROEX) and the Portal of Periodicals.

\section{References}

[1] V. M. Brennan, S. K. Kumanyika, and R. E. Zambrana, "Introduction: advancing a new conversation about obesity in the underserved. Obesity interventions in underserved communi- ties: evidence and directions," Johns Hopkins University Press, Baltimore (MD), 2014.

[2] S. Nam, "Obesity-related digestive diseases and their pathophysiology," Gut and Liver, vol. 11, no. 3, pp. 323-334, 2017.

[3] M. Razzoli, C. Pearson, S. Crow, and A. Bartolomucci, "Stress, overeating, and obesity: insights from human studies and preclinical models," Neuroscience \& Bio Behavioral Reviews, vol. 76, Part A, pp. 154-162, 2017.

[4] WHO, Health topics-obesity and overweight, WHO, 2020.

[5] S. B. Heymsfield and T. A. Wadden, "Mechanisms, pathophysiology, and management of obesity," New England Journal of Medicine, vol. 376, no. 3, pp. 254-266, 2017.

[6] A. Bianchi, A. Giampietro, L. Tartaglione et al., "Short- and long-term responsiveness to low dose growth hormone (GH) in adult GH deficiency: role of GH receptor polymorphism," Journal of Neuroendocrinology, vol. 31, no. 4, article e12692, 2019.

[7] M. Bouchoucha, M. Fysekidis, C. Julia et al., "Functional gastrointestinal disorders in obese patients. The importance of the enrollment source," Obesity Surgery, vol. 25, no. 11, pp. 2143-2152, 2015.

[8] A. Zilagyi, "Relationship(s) between obesity and inflammatory bowel diseases: possible intertwined pathogenic mechanisms," Clinical Journal of Gastroenterology, vol. 13, pp. 139-152, 2019.

[9] S. Singh, S. Picardo, and C. H. Seow, "Management of inflammatory bowel diseases in special populations: obese, old, or obstetric," Clinical Gastroenterology and Hepatology, vol. 18, no. 6, pp. 1367-1380, 2020.

[10] Y. Bhattarai, D. Fried, B. Gulbransen et al., "High-fat dietinduced obesity alters nitric oxide-mediated neuromuscular transmission and smooth muscle excitability in the mouse distal colon," American Journal of Physiology-Gastrointestinal and Liver Physiology, vol. 311, no. 2, pp. G210-G220, 2016.

[11] D. Pech-Puch, M. Pérez-Povedano, O. A. Lenis-Rojas, J. Rodríguez, and C. Jiménez, "Marine natural products from the Yucatan Peninsula," Marine Drugs, vol. 18, no. 1, p. 59, 2020.

[12] C. Wan-Loy and P. Siew-Moi, "Marine Algae as a Potential Source for anti-obesity agents," Marine Drugs, vol. 14, no. 12, p. 222, 2016.

[13] S. Gómez-Zorita, J. Trepiana, M. González-Arceo et al., “Antiobesity effects of microalgaee," International Journal of Molecular Sciences, vol. 21, no. 1, p. 41, 2020.

[14] M. Overland, L. T. Mydland, and A. Skrede, "Marine macroalgae as sources of protein and bioactive compounds in feed for monogastric animals," Journal of the Science of Food and Agriculture, vol. 99, pp. 13-24, 2018.

[15] A. R. J. Cabrita, M. Maia, H. M. Oliveira et al., "Tracing seaweeds as mineral sources for farm-animals," Journal of Applied Phycology, vol. 28, no. 5, pp. 3135-3150, 2016.

[16] H. Zeweil, I. M. Abaza, S. M. Zahran, M. H. Ahmed, A. E. HM, and A. A. Saad, "Effect of Spirulina platensis as dietary supplement on some biological traits for chicken sunder heat stress condition," Asian Journal of Biomedical and Pharmaceutical Sciences, vol. 6, no. 56, pp. 8-12, 2016.

[17] A. Finamore, M. Palmery, S. Bensehaila, and I. Peluso, "Antioxidant, Immunomodulating, and Microbial-Modulating Activities of the Sustainable and Ecofriendly Spirulina," Oxidative Medicine and Cellular Longevity, vol. 2017, Article ID 3247528, 14 pages, 2017. 
[18] M. M. Abdel-Daim, S. M. Farouk, F. F. Madkour, and S. S. Azab, "Anti-inflammatory and immunomodulatory effects of Spirulina platensis in comparison to Dunaliella salina in acetic acid-induced rat experimental colitis," Immunopharmacology and Immunotoxicology, vol. 37, no. 2, pp. 126-139, 2015.

[19] I. Michalak and K. M. Mahrose, "Seaweeds, intact and processed, as a valuable component of poultry Feeds," Journal of Marine Science and Engineering, vol. 8, no. 8, p. 620, 2020.

[20] H. Hajati and M. Zaghari, Spirulina Platensis in Poultry Nutrition, Cambridge Scholars Publishing Lady Stephenson Library, Newcastle upon Tyne, UK, 2019.

[21] M. M. Abdel-Daim, A. I. Abushouk, M. I. Alkhalf et al., "Antagonistic effects of Spirulina platensis on diazinoninduced hemato-biochemical alterations and oxidative stress in rats," Environmental Science and Pollution Research, vol. 25, no. 27, pp. 27463-27470, 2018.

[22] J. Zou, B. Chassaing, V. Singh et al., "Fiber-mediated nourishment of gut microbiota protects against diet-induced obesity by restoring IL-22-mediated colonic health," Cell Host \& Microbe, vol. 23, no. 1, pp. 41-53.e4, 2018.

[23] A. de Freitas Brito, A. S. Silva, A. A. de Souza et al., "Supplementation with Spirulina platensis modulates aortic vascular reactivity through nitric oxide and antioxidant activity," Oxidative Medicine and Cellular Longevity, vol. 2019, Article ID 7838149, 12 pages, 2019.

[24] A. Diniz, I. L. L. de Souza, E. dos Santos Ferreira et al., "Potential therapeutic role of dietary supplementation with Spirulina platensis on the erectile function of obese rats fed a hypercaloric diet," Oxidative Medicine and Cellular Longevity, vol. 2020, Article ID 3293065, 14 pages, 2020.

[25] L. Araujo, A. F. Brito, I. L. L. Souza et al., "Spirulina platensis supplementation coupled to strength exercise improves redox balance and reduces intestinal contractile reactivity in rat ileum," Marine Drugs, vol. 18, no. 2, p. 89, 2020.

[26] A. de Freitas Brito, A. S. Silva, C. V. C. de Oliveira et al., "Spirulina platensis prevents oxidative stress and inflammation promoted by strength training in rats: dose-response relation study," Scientific Reports, vol. 10, no. 1, pp. 1-8, 2020.

[27] E. Ferreira, Suplementação alimentar com Spirulina platensis promove efeito antiobesidade e restaura a reatividade contrátil de íleo em ratos Wistar, Universidade Federal da Paraíba, 2017.

[28] C. M. Sherwin, S. B. Christiansen, I. J. H. Duncan et al., "Guidelines for the ethical use of animals in applied ethology studies," Applied Animal Behaviour Science, vol. 81, no. 3, pp. 291-305, 2003.

[29] A. D. Campos, B. L. Diaz, E. A. Rivera et al., Guia brasileiro de produção, manutenção ou utilização de animais em atividades de ensino ou pesquisa científica: introdução geral, Ministério da Ciência, Tecnologia e Inovação, 2016.

[30] D. Estadella, L. M. Oyama, A. R. Dâmaso, E. B. Ribeiro, and C. M. Oller Do Nascimento, "Effect of palatable hyperlipidic diet on lipid metabolism of sedentary and exercised rats," Nutrition, vol. 20, no. 2, pp. 218-224, 2004.

[31] R. Deng and T. J. Chow, "Hypolipidemic, antioxidant, and antiinflammatory activities of microalgaee Spirulina," Cardiovascular Therapeutics, vol. 28, no. 4, 2010.

[32] I. L. L. Souza, B. C. Barros, G. A. Oliveira et al., "Hypercaloric diet establishes erectile dysfunction in rat: mechanisms underlying the endothelial damage," Frontiers in Physiology, vol. 8, pp. 1-15, 2017.
[33] I. L. L. de Souza, E. S. Ferreira, A. F. A. Diniz et al., "Effects of redox disturbances on intestinal contractile reactivity in rats fed with a hypercaloric diet," Oxidative Medicine and Cellular Longevity, vol. 2018, Article ID 6364821, 8 pages, 2018.

[34] M. Radenkovic, V. Ivetic, M. Popovic, N. Mimica-Dukic, and S. Veljkovic, "Neurophysiological effects of mistletoe (Viscum album L.) on isolated rat intestines," Phytotherapy Research, vol. 20, no. 5, pp. 374-377, 2006.

[35] M. Lee, "Determination of the SURFACE AREA of the white rat with its application to the expression of metabolic results," American Journal of Physiology, vol. 89, no. 1, pp. 24-33, 1929.

[36] E. Novelli, Y. S. Diniz, C. M. Galhardi et al., "Anthropometrical parameters and markers of obesity in rats," Laboratory Animals, vol. 41, no. 1, pp. 111-119, 2007.

[37] M. M. Mauer, R. B. Harris, and T. J. Bartness, "The regulation of total body fat: lessons learned from lipectomy studies," Neuroscience and Biobehavioral Review, vol. 25, no. 1, pp. 15-28, 2001.

[38] R. Surwit, M. N. Feinglos, J. Rodin et al., "Differential effects of fat and sucrose on the development of obesity and diabetes in C57BL/6J and AJ mice," Metabolism: Clinical and Experimental, vol. 44, no. 5, pp. 645-651, 1995.

[39] C. Santos, “Agonistas PPAR (Rosiglitazona, Bezafibrato e Fenofibrato) e alterações bioquímicas e estruturais em órgãos-alvo de camundongos C57BL/6 alimentados com dieta hiperlipídica rica em sacarose," in Tese (Doutorado em Biologia Humana e Experimental), Universidade do Estado do Rio de Janeiro, Rio de Janeiro, 2010.

[40] A. Stunkard and T. Wadden, Obesity: theory and therapy, vol. 1, Raven Press, New York, 2nd edition, 1993.

[41] D. J. Macrini, "Obesidade e reprodução: efeitos da privação alimentar materna na prole de ratos machos," in Tese (Doutorado em Patologia Ambiental e Experimental), Universidade Paulista, São Paulo, 2014.

[42] S. Bertoni, G. Gabella, P. Ghizzardi et al., "Motor responses of rat hypertrophic intestine following chronic obstruction," Neurogastroenterology and Motility, vol. 16, no. 3, pp. 365374, 2004.

[43] N. Jaiswal, G. Lambrecht, E. Mutschler, R. Tacker, and K. U. Malik, "Pharmacological characterization of the vascular muscarinic receptors mediating relaxation and contraction in rabbit aorta," Journal of Pharmacology and Experimental Therapeutics, vol. 258, no. 3, pp. 842-850, 1991.

[44] D. M. Juca, "Efeito do óleo essencial do eucalyptus tereticornis e dos constituintes 1, 8-cineol, $\alpha$-pineno e $\beta$-pineno na motilidade do músculo liso gastrointestinal de ratos," in Tese (Farmacologia), Universidade Federal do Ceará, 2012.

[45] R. Neubig, M. Spedding, T. Kenakin, A. Christopoulos, and International Union of Pharmacology Committee on Receptor Nomenclature and Drug Classification, "International union of pharmacology committee on receptor nomenclature and drug classification XXXVIII. Update on terms and symbols in quantitative pharmacology," Pharmacological Reviews, vol. 55, no. 4, pp. 597-606, 2003.

[46] A. Nascimento, M. M. Sugizaki, A. S. Leopoldo et al., "A hypercaloric pellet-diet cycle induces obesity and co-morbidities in Wistar rats," Arquivos Brasileiros de Endocrionologia e Metabologia, vol. 52, no. 6, pp. 968-974, 2008.

[47] J. Carroll, W. J. Zenebe, and T. B. Strange, "Cardiovascular function in a rat model of diet-induced obesity," Hypertension, vol. 48, no. 1, pp. 65-72, 2006. 
[48] M. T. L. Carvalho and B. A. Silva, "Efeito da dieta hipercalórica e da suplementação alimentar com Spirulina platensis sobre a reatividade intestinal de ratos Wistar," in Trabalho apresentado no Encontro de Iniciação Científica-ENIC, Universidade Federal da Paraíba, 2018.

[49] M. Moreira, D. I. G. Natal, R. C. L. Toledo et al., "Bacupari peel extracts (Garcinia brasiliensis) reduce high-fat diet- induced obesity in rats," Journal of Functional Foods, vol. 29, pp. 143153, 2017.

[50] A. Kassis, J. P. Godin, S. E. Moille et al., "Effects of protein quantity and type on diet induced thermogenesis in overweight adults: a randomized controlled trial," Clinical Nutrition, vol. 38, no. 4, pp. 1570-1580, 2019.

[51] A. B. Malafaia, P. A. N. Nassif, C. A. P. M. R. Ribas, B. L. Ariede, K. N. Sue, and M. A. Cruz, "Indução de obesidade com sacarose em ratos," Arquivos Brasileiros de Cirurgia Digestiva, vol. 26, Supplement 1, pp. 17-21, 2013.

[52] K. M. F. Silva, "Obesidade induzida por dieta em diferentes tempos: efeitos sobre análises murinométricas, hematológicas e imunológicas de ratas," in Tese (Doutorado em Nutrição), Universidade Federal de Pernambuco, Recife, 2014.

[53] S. Smith, J. C. Lovejoy, F. Greenway et al., "Contributions of total body fat, abdominal subcutaneous adipose tissue compartments, and visceral adipose tissue to the metabolic complications of obesity," Metabolism, vol. 50, no. 4, pp. 425-435, 2001.

[54] K. Frayn, "Adipose tissue as a buffer for daily lipid flux," Diabetologia, vol. 45, no. 9, pp. 1201-1210, 2002.

[55] L. Thibault, S. C. Woods, and M. S. Westerterp-Plantenga, "The utility of animal models of human energy homeostasis," British Journal of Nutrition, vol. 92, Supplement 1, pp. S41S45, 2004.

[56] M. Sata, H. Nishimatsu, J.-i. Osuga et al., "Statins augment collateral growth in response to ischemia but they do not promote cancer and atherosclerosis," Hypertension, vol. 43, no. 6, pp. 1214-1220, 2004.

[57] J. Zhang, L. Bricker, S. Wray, and S. Quenby, "Poor uterine contractility in obese women," BJOG: An International Journal of Obstetrics \& Gynaecology, vol. 114, no. 3, pp. 343-348, 2007.

[58] R. Muir, J. Ballan, B. Clifford et al., "Modelling maternal obesity: the effects of a chronic high-fat, high-cholesterol diet on uterine expression of contractile-associated proteins and ex vivo contractile activity during labour in the rat," Clinical Science, vol. 130, no. 3, pp. 183-192, 2016.

[59] T. C. Rosini, A. S. R. Silva, and C. Moraes, "Obesidade induzida por consumo de dieta: modelo em roedores para o estudo dos distúrbios relacionados com a obesidade," Revista de Associação Médica Brasileira, vol. 58, no. 3, pp. 383-387, 2012.

[60] R. A. R. Oliveira, “Avaliação da reatividade vascular e alterações morfológicas em artérias de ratos feitos obesos por uma dieta hiperlipídica associada à ingesta de frutose," in Dissertação (Mestrado em Ciências da Saúde), Universidade São Francisco, Bragança Paulista, São Paulo, 2013.

[61] S. Mustafa, "Effect of pregnancy on the cholinergic responses of the bladder: role of acetylcholinesterase," International Urology and Nephrology, vol. 51, no. 1, pp. 73-78, 2019.

[62] P. Simmers, S. K. Li, G. Kasting, and J. Heikenfeld, "Prolonged and localized sweat stimulation by iontophoretic delivery of the slowly-metabolized cholinergic agent carbachol," Journal of Dermatological Science, vol. 89, no. 1, pp. 40-51, 2018.
[63] X. Liu, B. Xia, H. K. Yu et al., "Atropine premedication facilitates ultrasound-guided reduction by saline enema in children with intussusception," Frontiers in Pharmacology, vol. 10, p. 43, 2019.

[64] T. J. Little, M. Horowitz, and C. Feinle-Bisset, "Modulation by high-fat diets of gastrointestinal function and hormones associated with the regulation of energy intake: implications for the pathophysiology of obesity," The American Journal of Clinical Nutrition, vol. 86, no. 3, pp. 531-541, 2007.

[65] A. Soares, E. J. Beraldi, P. E. B. Ferreira, R. B. Bazotte, and N. C. Buttow, "Intestinal and neuronal myenteric adaptations in the small intestine induced by a high-fat diet in mice," BMC Gastroenterology, vol. 15, no. 1, pp. 1-9, 2015.

[66] T. Pelaseyed, J. H. Bergström, J. K. Gustafsson et al., “The mucus and mucins of the goblet cells and enterocytes provide the first defense line of the gastrointestinal tract and interact with the immune system," Immunological Reviews, vol. 260, no. 1, pp. 8-20, 2014.

[67] M. Shan, M. Gentile, J. R. Yeiser et al., "Mucus enhances gut homeostasis and oral tolerance by delivering immunoregulatory signals," Science, vol. 342, no. 6157, pp. 447-453, 2013.

[68] M. E. V. Johansson and G. C. Hansson, "Mucus and the goblet cell," Digestive Diseases, vol. 31, no. 3-4, pp. 305-309, 2013.

[69] M. E. V. Johansson, H. Sjövall, and G. C. Hansson, “The gastrointestinal mucus system in health and disease," Nature Reviews Gastroenterology \& Hepatology, vol. 10, no. 6, pp. 352-361, 2013.

[70] M. S. Desai, A. M. Seekatz, N. M. Koropatkin et al., "A dietary fiber-deprived gut microbiota degrades the colonic mucus barrier and enhances pathogen susceptibility," Cell, vol. 167, no. 5, pp. 1339-1353.e21, 2016. 